\title{
Development of a multimedia model (POPsLTEA) to assess the influence of climate change on the fate and transport of polycyclic aromatic hydrocarbons in East Asia
}

\author{
Jee Hey Song, Yunah Lee, Dong Soo Lee* \\ Department of Environmental Planning and Environmental Planning Institute, Graduate School of Environmental Studies, Seoul National University, Seoul 08826, South Korea
}

\section{H I G H L I G H T S}

- A multimedia model (POPsLTEA) assesses climate change influence in East Asia.

- POPsLTEA was evaluated by comparing against multimedia monitoring data.

- POPsLTEA is applicable to semi-volatile organics including POPs and PAHs.

- A case of benzo(a)pyrene is presented in the multimedia environment under RCP8.5.

\section{G R A P H I C A L A B S T R A C T}

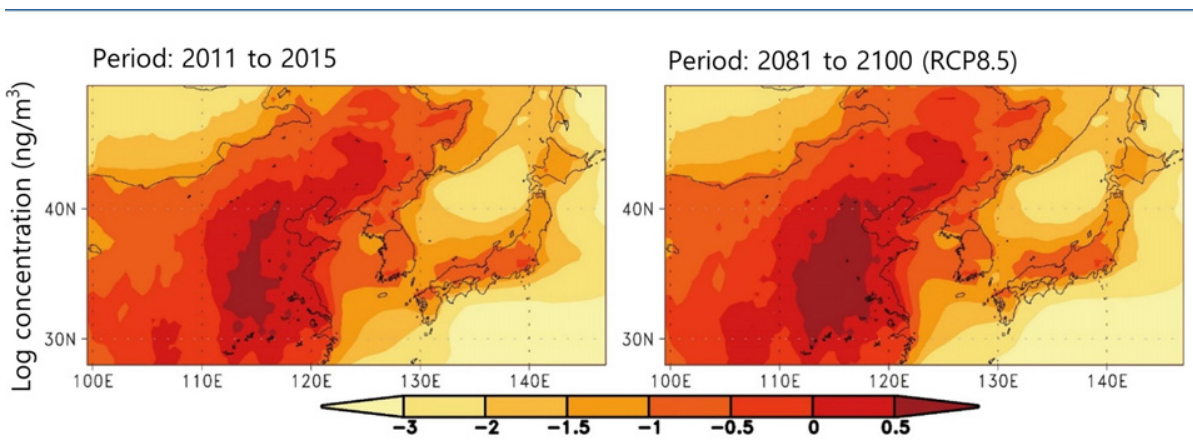

Change in the atmospheric concentration of benzo(a)pyrene predicted using POPSLTEA

\begin{abstract}
A B S T R A C T
A dynamic multimedia model (POPsLTEA) for an East Asia region was developed and evaluated to quantitatively assess how climate change (CC) alters the environmental fate and transport dynamics of 16 polycyclic aromatic hydrocarbons (PAHs) in air, water, soil, and sediment. To cover the entire model domain $\left(25^{\circ} \mathrm{N}-50^{\circ} \mathrm{N}\right.$ and $98^{\circ} \mathrm{E}-$ $148^{\circ} \mathrm{E}$ ) where China, Japan, and South and North Koreas are of primary concern, a total of 5000 main cells of $50 \mathrm{~km} \times 50 \mathrm{~km}$ size were used while 1008 cells of a finer spatial resolution $(12.5 \mathrm{~km} \times 12.5 \mathrm{~km})$ was nested for South Korea $\left(33^{\circ} \mathrm{N}-38^{\circ} \mathrm{N}\right.$ and $\left.126^{\circ} \mathrm{E}-132^{\circ} \mathrm{E}\right)$. Most of the predicted concentrations agreed with the observed values within one order of magnitude with a tendency of overestimation for air and sediment. Prediction of the atmospheric concentration was statistically significant in both coincidence and association, suggesting the model's potential to successfully predict the fate and transport of the PAHs as influenced by CC. An example study of benzo(a)pyrene demonstrates that direction and strength of the CC influence on the pollution levels vary with the location and environmental media. As compared to the five year period of 2011 to 2015, the changes across the model domain in the annual geometric mean concentration over the years of 2021 through 2100 were predicted to range from $88 \%$ to $304 \%$, from $84 \%$ to $109 \%$, from $32 \%$ to $362 \%$, and from $49 \%$ to $303 \%$, in air, soil, surface water, and sea water, respectively, under the scenario of RCP8.5.
\end{abstract}

(C) 2016 Elsevier B.V. All rights reserved.

\footnotetext{
* Corresponding author.

E-mail address: leeds@snu.ac.kr (D.S. Lee).
} 


\section{Introduction}

It is generally acknowledged that climate change (CC) can influence every step along the fate, transport, and distribution pathways of chemicals in the environment (Gusev et al., 2012; Dalla et al., 2007). Semi-volatile organic chemicals (SVOCs) including polycyclic aromatic hydrocarbons (PAHs) and persistent organic pollutants are of particular concern because CC can readily impact the quality of multiple environmental media because of the compounds' cross-media characteristics (Kallenborn et al., 2012; Teran et al., 2012; Schiedek et al., 2007).

The number of studies exploring the influence of CC on environmental fate and transport of pollutants seems to be growing (Marquès et al., 2016; Hansen et al., 2015; Nadal et al., 2015; Cai et al., 2014; Kallenborn et al., 2012; Noyes et al., 2009; Macdonald et al., 2003). Previous studies often addressed effects of individual climate parameters (Noyes et al., 2009; Dalla et al., 2007; Schiedek et al., 2007; Wania and Daly, 2002) and/or effects on a pollution level in a single medium (Amell et al., 2015; Harley et al., 2006; Macdonald et al., 2003) In these studies, the complicated and interdependent natures among the parameters and/ or the environmental media were generally left out. Also, quantitative assessment of the CC influence has been limited (Balbus et al., 2013; Lamon et al., 2009a; MacLeod et al., 2005; Dalla et al., 2003).

To overcome these limitations, multimedia models may serve as an excellent tool which can assess the CC influence in quantitative and integrated manners on the pollution level in multiple environmental media. Macleod et al. (2005) and Earnshaw et al. (2015) predicted by using a level III multimedia model the pollution distribution of polychlorinated biphenyls (PCBs) and polybrominated diphenyl ethers (PBDEs) as influenced by the weather change for a period of 50 years at global and European scales. Also, Globo-POP (Wania and Mackay, 1999) was used to analyze the importance of hydroxyl radical (Wania and Daly, 2002) and temperature (Wania, 2003) to the transport of PCBs while BETR-Global (Macleod et al., 2001, 2005) was used to predict that higher temperature under a climate change scenario causes increase in the atmospheric concentration of PCBs (Lamon et al., 2009b). Zhu et al. (2014) demonstrated using SESAMe that potential longrange transport of pollutants can change significantly with a change in wind speed in China.

According to the study objectives, however, these previous studies used multimedia models that adopt assumptions of equilibrium among the environmental compartments and/or steady state with which dynamic nature of the CC influences cannot be readily captured. Also, the pollutants of concern in the model studies were limited to typical persistent organic pollutants such as PCBs and PCDDs/DFs (Nadal et al., 2015).

Long range transport of pollutants among East Asian countries has already been an important issue including SOx (Wang et al., 2008), sulfate and nitrate (Fairlie et al., 2010), heavy metals (Kusunoki et al., 2012), and polybrominated biphenyls (Law et al., 2014). With growing industrialization and economy in these countries, more number of hazardous substances are likely to be emitted with increasing quantity, which will add to the significance of the long range transport issues. Besides, quantitative understanding of the impacts of CC on the long range transport is critical to managing the future environmental quality of this region. However, existing modeling studies focused mostly on Europe or the globe (MacLeod et al., 2011; Hauck et al., 2008) while only a few studies have been conducted on CC influence in the multimedia environment which are limited to individual countries such as China (Liu et al., 2014) and South Korea (Cai et al., 2014). In the absence of an adequate multimedia model to address issues of long range transport of various SVOCs including persistent organic pollutants (POPs) and PAHs, we developed a dynamic multimedia fate and transport model (Persistent Organic Pollutants Long Range Transport model for East Asia, POPsLTEA) for an East Asia region aiming to quantitatively assess how the long range transport dynamics in the multimedia environment vary with climate change. In the present work, the development of
POPSLTEA and its evaluation results for the 16 PAHs were presented. The PAHs from pyrogenic sources (Lee et al., 2004) were selected because many of them possess POPs characteristics (OSPAR) and they are ubiquitous pollutants of great environmental concern (Tobiszewski and Namiesnik, 2012) and their atmospheric emission will continue in the region.

\section{Materials and methods}

\subsection{Climate change scenario}

Meteorological data used in this study comprised of reanalysis data based on the observation and predicted data under the RCP8.5 scenario for the periods from 1956 to 2005 and from 2006 to 2100 , respectively. The RCP8.5 data were produced by HadGEM2-AO (Jones et al., 2011; Stott et al., 2006) developed in the Coupled Model Inter-comparison Project (CMIP5) with the horizontal resolution of $135 \mathrm{~km} \times 135 \mathrm{~km}$. The resolution was then scaled down for $50 \mathrm{~km} \times 50 \mathrm{~km}$ and $12.5 \mathrm{~km} \times 12.5 \mathrm{~km}$ for the East Asia and South Korea (NIMR, 2011), respectively. Need of the finer resolution for South Korea was recognized in the model design phase for more detailed analysis. The data indicates that temperature in the study area rises by about $7^{\circ} \mathrm{C}$ over the 145 years (1956 to 2100) (Fig. 1(a)), which is greater than the global average of $3.7 \pm 0.74{ }^{\circ} \mathrm{C}$ (NIMR, 2012). The annual average temperature and the precipitation is statistically not the same among the three countries and sea while the increasing rates in temperature and precipitation with time shows no statistical difference (Levene and Dunnett T3 tests). It was notable that fluctuation in the annual precipitation is greater in South Korea than in others (Fig. 1(b)). The difference in the averaged wind vector between the two periods (2081 to 2100 and 1986 to 2005) is shown in Fig. 1(c) and (d) for the atmospheric layers of $1000 \mathrm{hPa}$ (altitude of around $100 \mathrm{~m}$ ) and $850 \mathrm{hPa}$ (altitude between $1100 \mathrm{~m}$ and $2100 \mathrm{~m}$ ), respectively. The main features of the lower layer are increase of north wind in southern China and increase of west wind in the high latitudes of the Pacific. In the higher layer, southwest wind increases in south east China and southwest coast of South Korea while west wind increases over high latitudes of the Pacific. The $850 \mathrm{hPa}$ layer is of particular concern for long range transport of pollutants in the study area.

\subsection{POPSLTEA}

The domain of POPsLTEA covers the region of $25^{\circ} \mathrm{N}-50^{\circ} \mathrm{N}$ and $98^{\circ} \mathrm{E}-$ $148^{\circ} \mathrm{E}$ as shown in Fig. 2, including eastern China, the Korean peninsula, and Japan. A small part of each of Mongolia and Russia is also within the domain. The environmental media modeled in POPsLTEA are air, soil, water (fresh water and sea water), sediment, and vegetation as individual compartments. Each of the air and the water compartments consists of two sub-compartments i.e., vapor and particulate matters in air and dissolved phase and suspended solids in surface water where chemical equilibrium was assumed between the two sub-compartments.

The multimedia structure of the individual model cells in POPsLTEA is schematically shown in Fig. S1. With homogeneous mixing assumption for chemicals in individual compartments of a given cell, POPSLTEA is mathematically a set of ordinary differential equations which can generally be expressed for the compartment $\mathrm{i}$ in the cell $\mathrm{n}$ as

$$
\begin{aligned}
& \frac{d\left(\mathrm{~V}_{\mathrm{i}} \mathrm{C}_{\mathrm{i}}\right)_{\mathrm{n}}}{d \mathrm{t}}=\left[\sum_{\mathrm{j}=1}^{\mathrm{N}_{\mathrm{i}}} \mathrm{A}_{\mathrm{ij}} \mathrm{k}_{\mathrm{ij}}^{\mathrm{o}}\left(\mathrm{C}_{\mathrm{ij}}{ }^{*}-\mathrm{C}_{\mathrm{i}}\right)+\sum_{\mathrm{k}=1}^{\mathrm{M}_{\mathrm{ij}}} \sum_{\mathrm{j}=1}^{\mathrm{N}_{\mathrm{i}}} \mathrm{A}_{\mathrm{ijk}}\left(\mathrm{F}_{\mathrm{ji}}{ }^{\mathrm{k}}-\mathrm{F}_{\mathrm{ij}}{ }^{\mathrm{k}}\right)\right] \mathrm{x}_{\mathrm{n}} \\
& +\left[\sum_{\mathrm{p}=1}^{\mathrm{N}_{\mathrm{p}}} \mathrm{A}_{\mathrm{np}}\left(\mathrm{D}_{\mathrm{np}}^{\mathrm{t}}\left(\mathrm{C}_{\mathrm{p}}-\mathrm{C}_{\mathrm{n}}\right) / \Delta \mathrm{x}_{\mathrm{np}}+\left(\mathrm{U}_{\mathrm{pn}} \mathrm{C}_{\mathrm{p}}-\mathrm{U}_{\mathrm{np}} \mathrm{C}_{\mathrm{n}}\right)\right)\right]_{\mathrm{i}}+\left(R_{i n}+S_{i n}\right) V_{i n}
\end{aligned}
$$

$(i \neq j, n \neq p)$

$\mathrm{V}_{\mathrm{i}}$ : volume of the compartment $\mathrm{i}$

$\mathrm{C}_{\mathrm{i}}$ : concentration of a chemical of interest in $\mathrm{i}$

$\mathrm{N}_{\mathrm{i}}$ : total number of compartments exchanging the chemical with $\mathrm{i}$ 
(a) Temperature

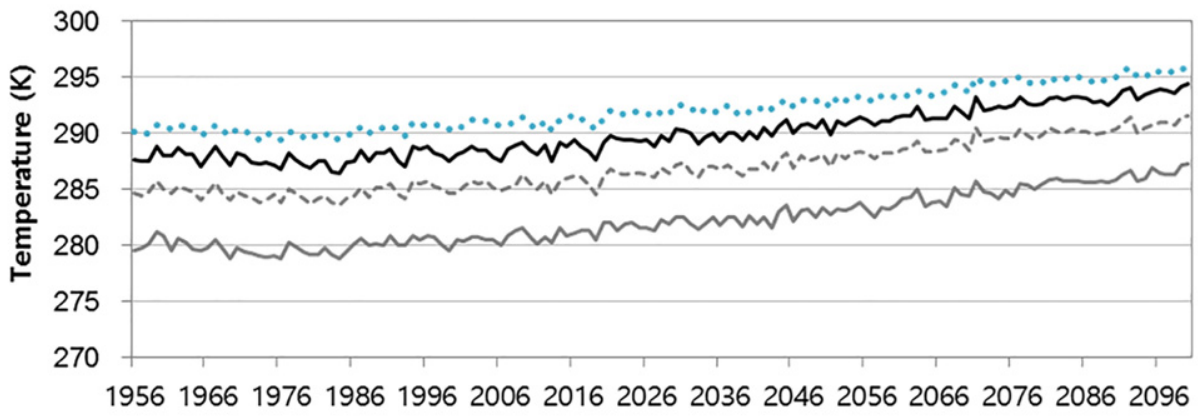

(b) Precipitation

China ----Japan - South Korea .... sea

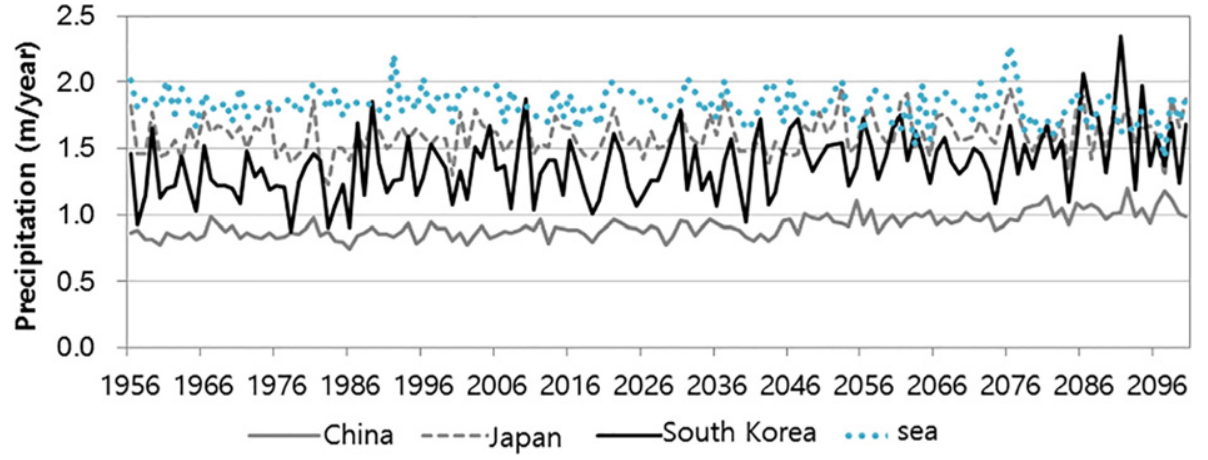

(c) Change in wind at $1000 \mathrm{hPa}$ level

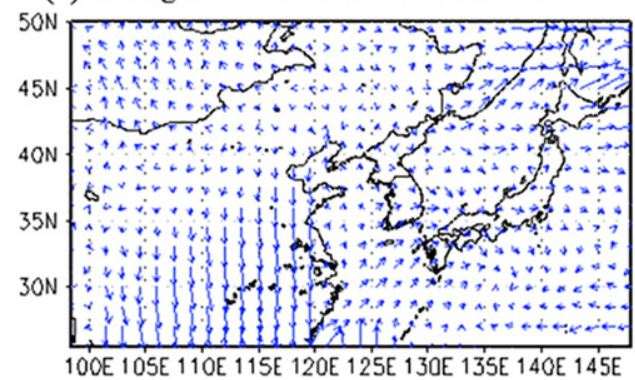

$\longrightarrow \mathrm{m} / \mathrm{s}$ (d) Change in wind at $850 \mathrm{hPa}$ level

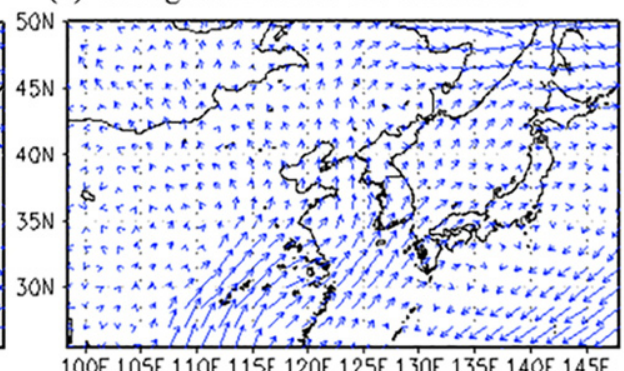

$2 \mathrm{~m} / \mathrm{s}$

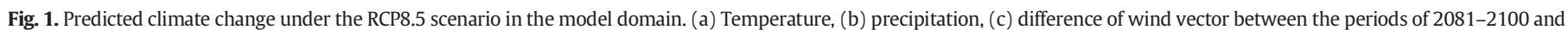
1986-2005 at $1000 \mathrm{hPa}$ and (d) $850 \mathrm{hPa}$.

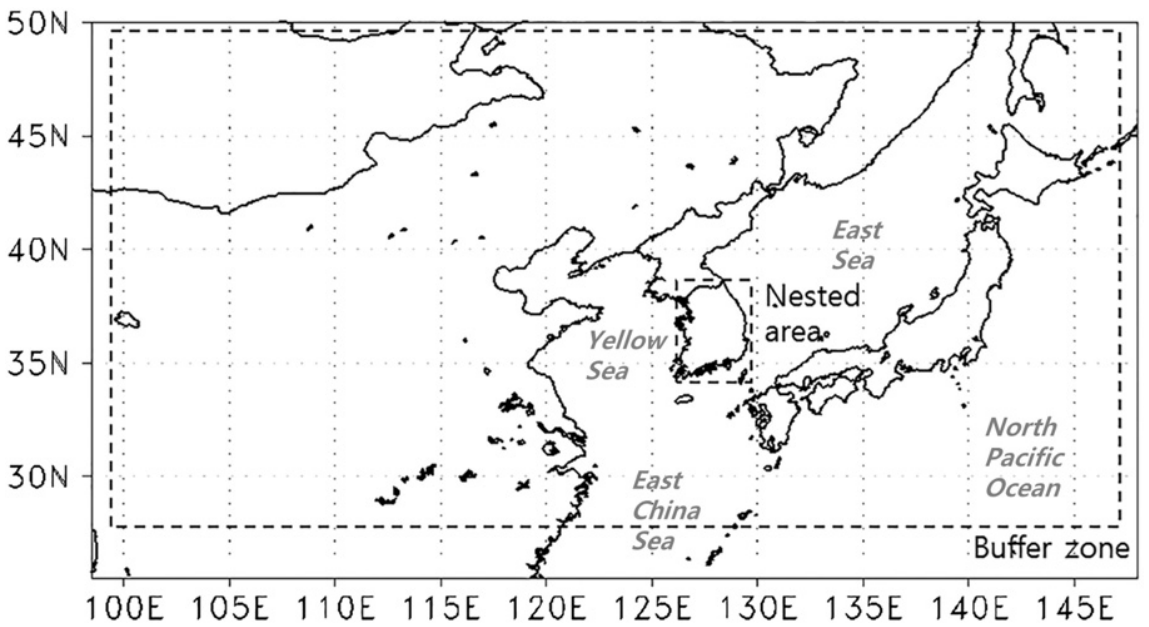

Fig. 2. The model domain of POPsLTEA including the nested area and the buffer zone. 
$A_{\mathrm{ij}}$ : interfacial area between the compartments $\mathrm{i}$ and $\mathrm{j}$

$\mathrm{k}_{\mathrm{ij}}^{\mathrm{o}}$ : i-side overall mass transfer coefficient between $\mathrm{i}$ and $\mathrm{j}$

$C_{i j}^{*}$ : concentration in $i$ in equilibrium with the concentration in $j$

$\mathrm{F}_{\mathrm{ij}}^{\mathrm{k}}$ and $\mathrm{F}_{\mathrm{ji}}^{\mathrm{k}}$ : cross-compartment fluxes from i to $\mathrm{j}$ and from $\mathrm{j}$ to $\mathrm{i}$, respectively, by non-diffusive transport process $\mathrm{k}$

$\mathrm{M}_{\mathrm{ij}}$ : total number of non-diffusive processes transporting the chemicals between $\mathrm{i}$ and $\mathrm{j}$

$\mathrm{A}_{\mathrm{ijk}}$ : area available for the process $\mathrm{k}$ to chemical transport between $\mathrm{i}$ and $\mathrm{j}$ $\mathrm{N}_{\mathrm{p}}$ : total number of cells exchanging the chemical with the cell $\mathrm{n}$

$A_{n p}$ : interfacial area between the cells $n$ and $p$

$\mathrm{D}_{\mathrm{np}}^{\mathrm{t}}$ : average turbulent diffusion coefficient of $\mathrm{n}$ and $\mathrm{p}$

$\mathrm{C}_{\mathrm{n}}$ and $\mathrm{C}_{\mathrm{p}}$ : pollutant concentration in $\mathrm{n}$ and $\mathrm{p}$, respectively

$\mathrm{x}_{\mathrm{np}}$ : distance between the centers of $\mathrm{n}$ and $\mathrm{p}$

$\mathrm{U}_{\mathrm{pn}}$ and $\mathrm{U}_{\mathrm{np}}$ : advective velocity of bulk compartment from $\mathrm{p}$ to $\mathrm{n}$ and from $\mathrm{n}$ to $\mathrm{p}$, respectively

$R_{\text {in }}$ : reaction rate of the chemical per unit volume of $i$ in the cell $n$

$S_{\text {in }}$ : source strength per unit volume of $i$ in the cell nwhere the 1 st and the 2nd terms on the right hand side of the equation denote chemical exchanges between two compartments ( $\mathrm{i}$ and $\mathrm{j}$ ) within a cell $(\mathrm{n})$ by diffusive and non-diffusive processes, respectively. The 3rd and the 4th terms denote chemical exchanges between the cells ( $n$ and $p$ ) by turbulent diffusion and advection, respectively, in the compartment i. Major processes and variables are listed in Tables S1 and S2 of Supplementary Data (SD).

To account for the CC influences, equations and parameters describing the intra- and inter-compartmental processes in the model were expressed as a function of temperature, wind speed, rain rate, radiation intensity ( short wave), and relative humidity as necessary (Table S3).

\subsection{Input data}

\subsubsection{Geophysical data}

Geospatial data for the model domain are divided largely into the soil, surface water, and marine data groups. Soil data was obtained from the International Geosphere Biosphere Programme (IGBP) - Moderate Resolution Imaging Spectroradiometer (MODIS) (IGBP-MODIS land cover) that National Oceanic and Atmospheric Administration provides using MODIS satellite data. Data with resolution of $0.083333^{\circ}$ (about $8.3 \mathrm{~km}$ ) was used for the East Asian region and data with resolution of $0.008333^{\circ}$ (about $0.83 \mathrm{~km}$ ) was used for the nested Korea region. Flow direction data of fresh water in the model domain was taken from HYDRO1K (USGS Long term archive). The data of current speed and direction in the sea surface was obtained from Ocean Surface Current Analyses Real time (OSCAR).

\subsubsection{Chemical data}

The temperature dependency of the physico-chemical and environmental fate properties of the 16 PAHs (with abbreviated names) are summarized in Tables S4 and S5.

\subsubsection{Emission data}

Quantitative information on the spatial distribution of the PAHs emission was very limited in the model domain. At country level, the emission estimates of the 16 individual PAHs by Zhang and Tao (2009) that were calculated using emission factors and emission activity in 2004 were adopted in the present work. Spatial allocation of the emission estimates within China was done using the regional proportions calculated by Xu et al. (2006). For South Korea, the local rates set out in a previous report (KME, 2008) were applied. The spatial allocation for Japan and North Korea was done in proportion to the population density distribution (Demographia World Urban Areas, 2014). As was done in previous studies (Lin et al., 2011; Shen et al., 2011; Zhang et al., 2007; Xu et al., 2006), the temporal change of the emission estimates was calculated corresponding to the change in gross domestic product (GDP) of the individual countries (China, South Korea, North Korea, Japan, Mongolia, and Russia) in the model domain (World
Bank; The Maddison-Project, 2013). While the GDP corrected emission estimates were used for the period from 1956 to 2013, emission was assumed constant from 2014 to 2100 for two reasons. First, assessing the influence of climate variables would become extremely complicated if the temporal change in the emission estimate were used for the future because then the influence of changing emission should be separated from that of the climate variables. Second, estimating the emission over a period of about 90 future years would inevitably produce huge uncertainties which may be inadequate for the modeling purposes in the present work.

\subsection{Buffer zone}

In the lack of reliable boundary conditions (BCs), a buffer zone (areas for which simulation results strongly vary with the BCs used) was determined following Liang et al. (2001) to exclude the simulation results of the zone from later analyses. For the determination of the buffer zone, simulation results from two limiting BCs were compared with each other. The first BC signifies low level cross-boundary exchange of pollutants by assuming that the concentrations in the boundary cells are equal to those in the locations immediately exterior to the boundary cells $(\Delta C=0)$. The second $\mathrm{BC}$ assumes all the concentrations outside the model domain to be zero, which represents the case of maximum cross-boundary flux. As shown in Fig. S2, the ratio of the concentrations from the two $\mathrm{BCs}$ (= Concentration ${ }_{1 \mathrm{st} \mathrm{BC}} /$ Concentration $_{2 \mathrm{nd} \mathrm{BC}}$ ) tends to grow rapidly near the boundaries. The buffer zone was defined in the present work as the border areas where the ratio is greater than 1.5 (i.e., difference of 50\%) in the 4th atmospheric layer that is most relevant to the long range transport in the study area. According to the definition, the buffer zone comprised of 2 columns of cells from each of the western and eastern boundaries and 5 rows and 1 row of cells from southern and northern boundaries, respectively. The size of the buffer zone in the 4th layer is $15.5 \%$ of the model domain and shrinks to $5 \%$ in the first atmospheric layer.

\subsection{Model evaluation}

Model evaluation was performed in three steps. First, the model structure, process equations, and parameters were reexamined for their adequacy and accuracy. Second, mathematical exactness was examined by checking the model calculations at the levels of individual processes and chemical mass balance for individual media in selected cells and the entire model domain. Third, predicted concentration was compared against monitoring data in two ways depending on the availability of the monitoring data, i.e., i) semiquantitative comparison of mean and/or range if without individual data values and ii) quantitative comparison of individual data for their coincidence and association between the predicted and measured values. The coincidence, as assessed by the lack of fit analysis (Smith and Smith, 2007), refers to the degree of difference between predicted and measured values. The degree of association determined from the correlation coefficient and the number of data point indicates how well model prediction meets the trends of observation. The degree of association is particularly important in the present work for assessing the model's capability to account for the influences of weather and other variables on the environmental concentrations. The details of the statistical analyses are provided in SD (Coincidence and association analyses).

Five PAHs (Nap, Phe, Flr, BaP, and BghiP) were selected for the third step of model evaluation as they can collectively encompass the chemical property ranges of the 16 PAHs. For China and Japan, monitoring data of only mean and/or range values were available in most of the accessible literatures while individual data values and the monitoring conditions were obtained for South Korea. 


\section{Results and discussion}

\subsection{Features of POPSLTEA}

A dynamic multimedia model, POPsLTEA, was developed to assess influences of climate change on the fate and transport of POPs and PAHs in air, water, soil, sediment, and vegetation of east Asia $\left(25^{\circ} \mathrm{N}-\right.$ $50^{\circ} \mathrm{N}$ and $98^{\circ} \mathrm{E}-148^{\circ} \mathrm{E}$ ) where China, Japan, and South and North Koreas are the countries of primary concern. The model domain consists of a total of 5000 main cells ( 100 in the east-west direction $\times 50$ in the north-south direction) of $50 \mathrm{~km} \times 50 \mathrm{~km}$ size. To get more detailed results for South Korea $\left(33^{\circ} \mathrm{N}-38^{\circ} \mathrm{N}\right.$ and $\left.126^{\circ} \mathrm{E}-132^{\circ} \mathrm{E}\right)$, a finer spatial resolution $(12.5 \mathrm{~km} \times 12.5 \mathrm{~km})$ was adopted using the one way nesting method (Jacobson, 2005). In the nested area are 1008 cells (36 in the east-west direction $\times 28$ in the south-north direction) bordered with 16 main cells. The individual air cells are composed of 4 layers (height of top surface of each layer: $100 \mathrm{~m}, 400 \mathrm{~m}, 1100 \mathrm{~m}$, and $2100 \mathrm{~m}$ ) to account for the height dependent fate and transport of the compounds.

POPsLTEA consists of 16 modules and 90 subroutines as listed in Fig. S3. A total of 8 subroutines are dedicated to calculation of the atmospheric processes while 11 of subroutines are shared to calculate the processes in soil, water, sediment, and vegetation. As illustrated in Fig. 3, calculation of the atmospheric processes precedes that of the processes in other media. Major model output includes the concentrations in the multi-media and intra- and inter-media fluxes in time and space, which are stored for later analyses. The nested area is simulated in the same ways as the East Asian region with the use of calculation results of the 16 surrounding main cells as a boundary condition. A default computation time step of $3 \mathrm{~h}$ is used although the time step was adjusted down to $30 \mathrm{~s}$ as necessary for efficient computation while avoiding numerical instability. The Euler method with operator splitting technique (Jacobson, 2005) was used to solve the sets of mass balance equations.

The model was programmed by Fortran 90 in a Linux system using PGI compiler. The compiler options were chosen for memory expansion to simultaneously compile multiple modules and subroutines. The input and output files are in binary form and the computation result files for graphs and statistical work are saved as ASCII files.

\subsection{Evaluation of POPSLTEA}

Prior to model evaluation against the monitoring data, it was confirmed that mass balance is closed with the prescribed error $\left(10^{-5} \%\right)$ of the total mass of emission for the simulation period of 145 years.

\subsubsection{Overall comparison of the model prediction with observed concentra-} tions in multimedia

For the evaluation of POPsLTEA, monitoring data of Nap, Phe, Flr, BaP, and BghiP were collected from 12, 22, and 10 areas in China, Japan, and

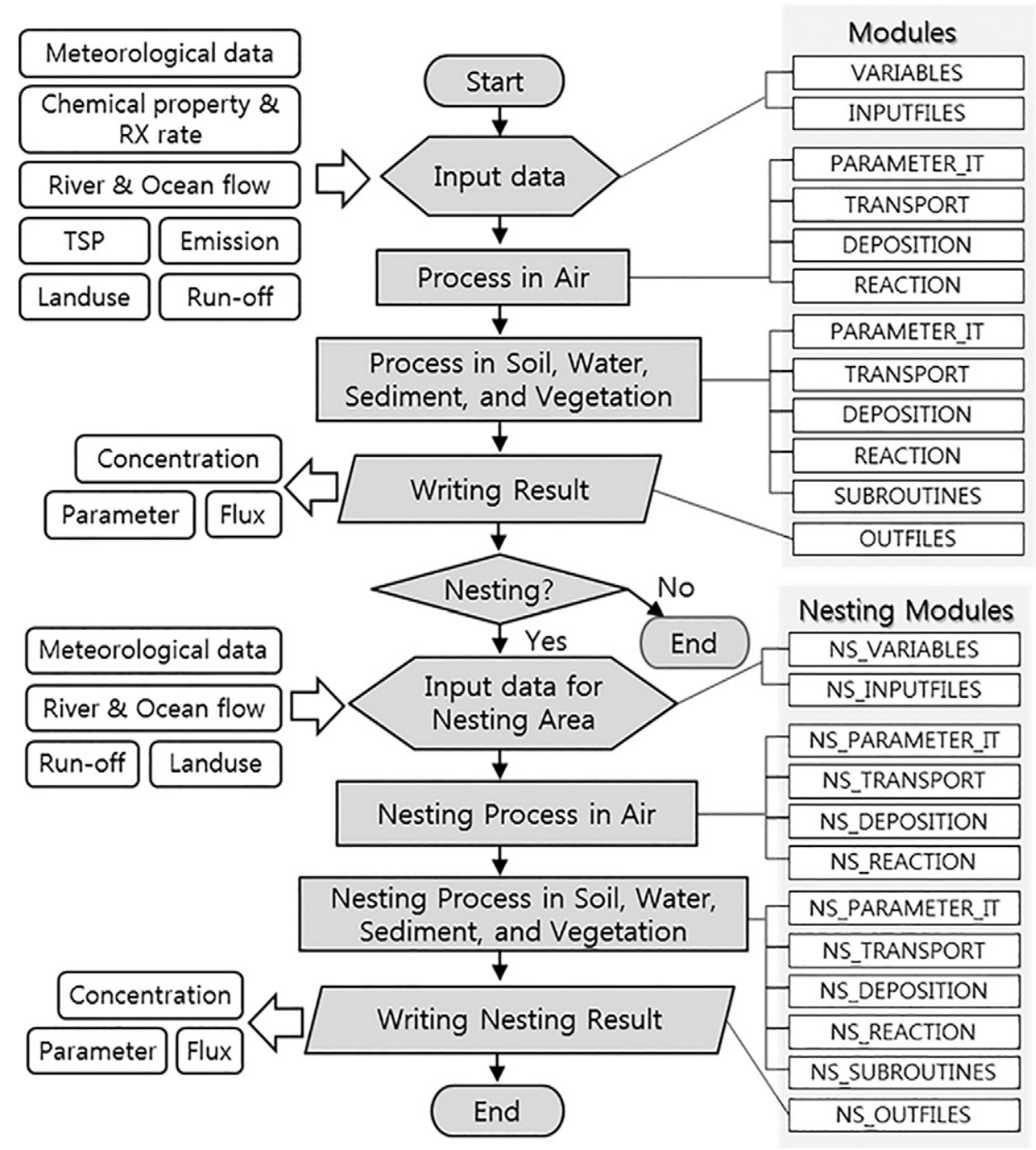

Fig. 3. Computation sequence of POPsLTEA. 
(a) Air

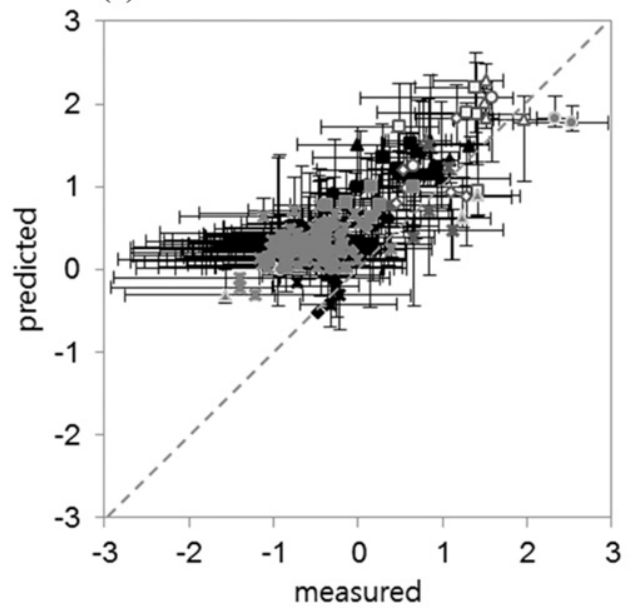

(c) Soil

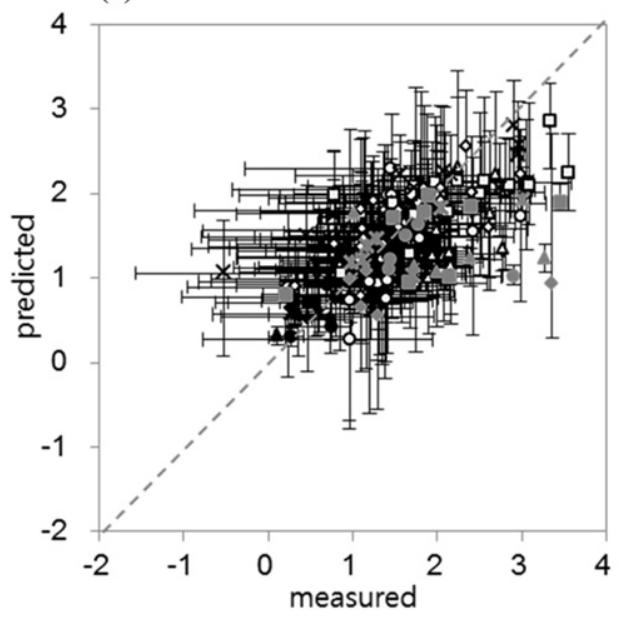

(b) Fresh Water

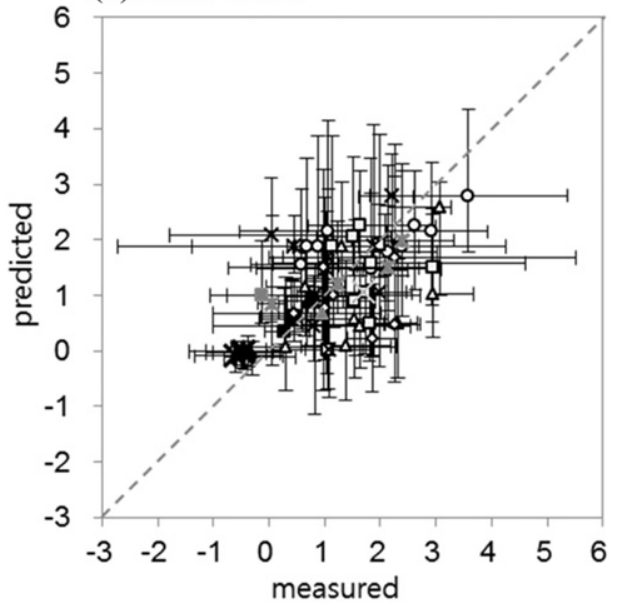

(d) Sediment

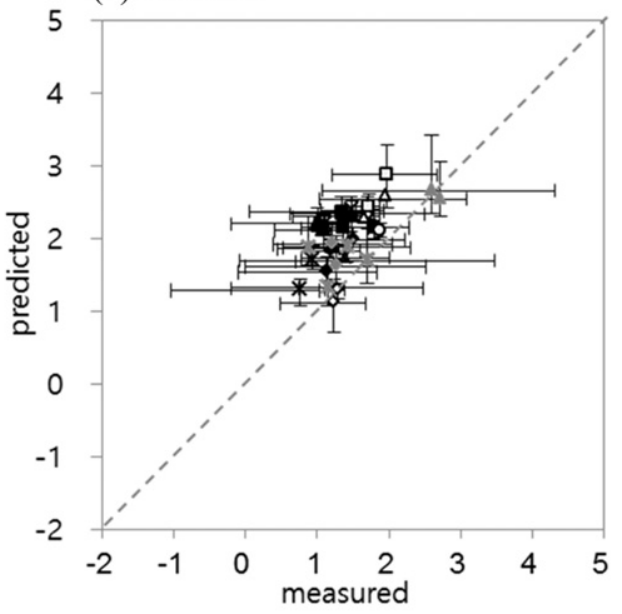

\begin{tabular}{|lll|} 
South Korea Nap & $\bigcirc$ China Nap & Japan Nap \\
South Korea Phe & $\triangle$ China Phe & $\triangle$ Japan Phe \\
South Korea Flr & $\square$ China Flr & Japan Flr \\
× South Korea BaP & $\times$ China BaP & $\times$ Japan BaP \\
South Korea Bghip & $\diamond$ China BghiP & $\checkmark$ Japan BghiP \\
\hline
\end{tabular}

Fig. 4. Comparison of predicted and measured log concentrations of Nap, Phe, Flr, BaP, and BghiP for (a) air [ng/m³], (b) fresh water [ng/l], (c) soil [ng/g], and (d) sediment [ng/g].

South Korea, respectively (Table S6). The overall picture of the comparison is shown in Fig. 4. The model tends to overestimate for air and sediment while showing no such tendency for water and soil. In general, most of the predicted concentrations agreed with the observed values with deviations less than one order of magnitude. However, the deviations occasionally increased up to three orders of magnitude for the concentrations in water and soil of China and Japan, respectively. The differences between prediction and observation might be ascribable to inaccuracies of input data including emission rate as well as environmental and weather conditions used for the model. Particularly, uncertainties associated with the temporal change in flow rate and volume of the surface streams were considered larger in China due to limited data available for the present study. Besides, the predicted and the monitoring data did not exactly match with each other in location because of the spatial resolution used in the model. It is noteworthy that the deviations were less than one order of magnitude for all the compounds and media

Table 1

Statistical comparison between the measured and the predicted concentrations for 5 PAHs in air, soil, water, and sediment.

\begin{tabular}{|c|c|c|c|c|c|c|c|c|c|c|c|c|}
\hline & \multicolumn{4}{|c|}{ South Korea } & \multicolumn{4}{|c|}{ China } & \multicolumn{4}{|c|}{ Japan } \\
\hline & Air & Soil & Water & Sed. & Air & Soil & Water & Sed. & Air & Soil & Water & Sed. \\
\hline Nap & 0.33 & 0.29 & & & 0.48 & 0.49 & 0.76 & 0.29 & 0.93 & 0.10 & & \\
\hline Phe & 0.21 & 0.10 & 0.32 & 0.16 & 0.35 & 0.03 & 0.68 & 0.19 & 0.76 & 0.23 & 0.14 & 0.09 \\
\hline $\mathrm{Flr}$ & $\overline{0.10}$ & 0.74 & 0.29 & 0.16 & 0.69 & 0.43 & 0.22 & 0.21 & 0.10 & 0.30 & 0.12 & \\
\hline $\mathrm{BaP}$ & 0.33 & 0.25 & 0.09 & $\overline{0.21}$ & 0.87 & 0.36 & 0.4 & 0.19 & 0.05 & 0.52 & 0.91 & 0.18 \\
\hline BghiP & 0.14 & 0.62 & 0.11 & 0.18 & 0.28 & 0.62 & 0.14 & 0.13 & 0.24 & 0.17 & & 0.22 \\
\hline
\end{tabular}

The $p$-values from $t$-test (in Italics) and Mann-Whitney test (underlined) at the $90 \%$ confidence level. 
Table 2

Performance of POPsLTEA indicated by coincidence and association.

\begin{tabular}{llrrrrr}
\hline & & Critical F & \multicolumn{1}{l}{ Phe } & \multicolumn{1}{c}{ Flr } & \multicolumn{1}{c}{ BaP } & \multicolumn{1}{c}{ BghiP } \\
\hline \multirow{2}{*}{ Air } & Coincidence & 1.87 & 1.103 & 1.861 & 0.829 & 0.132 \\
& Association & 4.06 & 10.1182 & 11.242 & 6.090 & 6.197 \\
\multirow{2}{*}{ Soil } & Coincidence & 2.33 & 1.640 & 2.014 & 0.605 & 0.995 \\
& Association & 39.86 & 131.674 & 110.191 & 24.898 & 11.754 \\
\multirow{4}{*}{ Sater } & Coincidence & 2.23 & 3.470 & 6.704 & 18.805 & 1.506 \\
& Association & 39.86 & 15.516 & 337.068 & 29.710 & 138.916 \\
& Coincidence & 2.23 & 3.005 & 2.519 & 0.429 & 2.867 \\
& Association & 39.86 & 33.051 & 66.068 & 171.627 & 24.562 \\
\hline
\end{tabular}

${ }^{a}$ Coincidence and association are statistically significant if $\mathrm{F}$ value $<$ critical $\mathrm{F}$ and $\mathrm{F}$ value $>$ critical F, respectively.

in South Korea where the input uncertainties were smaller and the finer spatial resolution was used.

Despite the apparent deviations of model prediction from observation, $t$-test and Mann-Whitney test with $90 \%$ confidence indicated that the predicted concentrations are not significantly different from the observed data except for Phe in soil of China, BaP in air and Phe in sediment of Japan, and BaP in water of South Korea (Table 1). It should be noted, however, that even the statistically different predictions from the observed ones were biased mostly within one order of magnitude. It was found in Japan that the difference between the prediction and the observation of Nap, Phe, Flr, BaP, and BghiP in air, soil, water, and sediment for the years prior to 2004 increased with the temporal distance from 2004, indicating that the difference was likely to arise from growing uncertainties in emission estimate that was back-calculated using 2004 as a reference year.

\subsubsection{Coincidence and association}

For the coincidence and the association analyses, only the observed data of South Korea could be used because individual data and detailed information of the sampling conditions were available. The coincidence analysis with $90 \%$ confidence showed that prediction is not statistically different from those observed for all the 5 PAHs concentrations in air and soil (Table 2). However, the concentrations of Phe, Flr, and BaP in

(a)
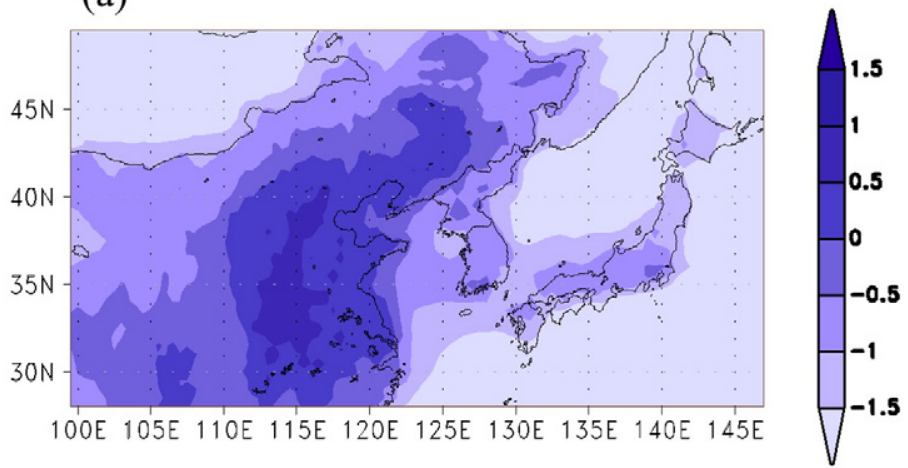

(b)

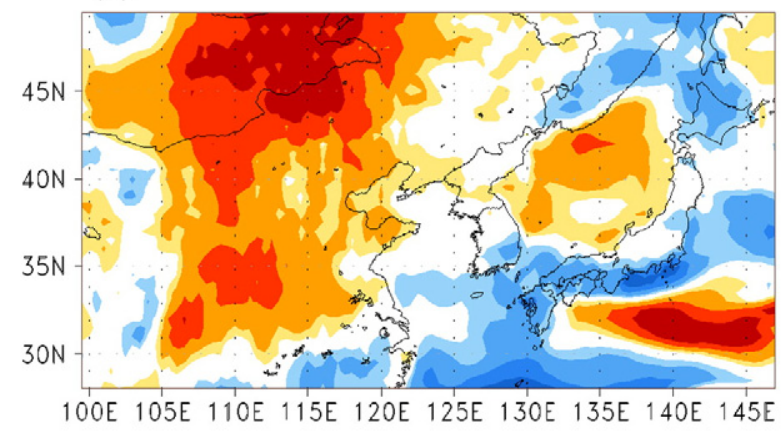

(c)

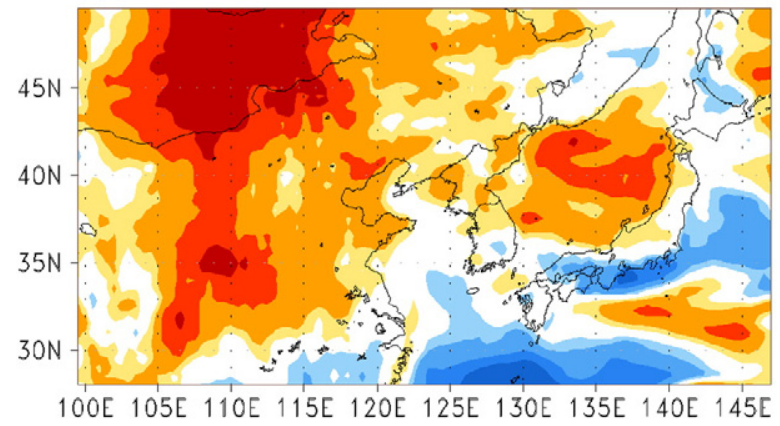

(d)

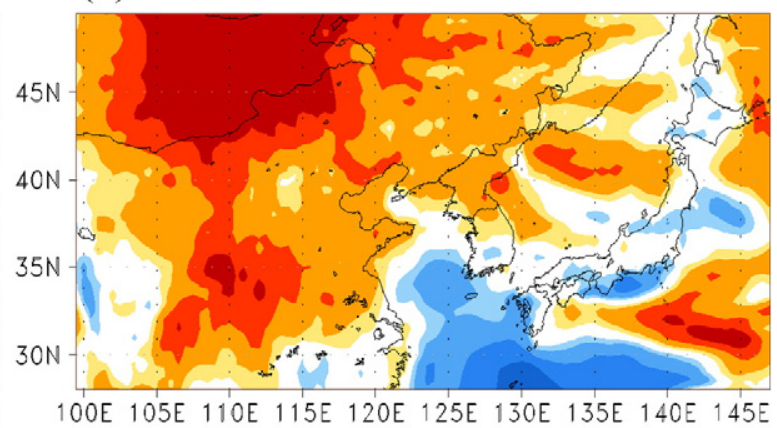

(e)

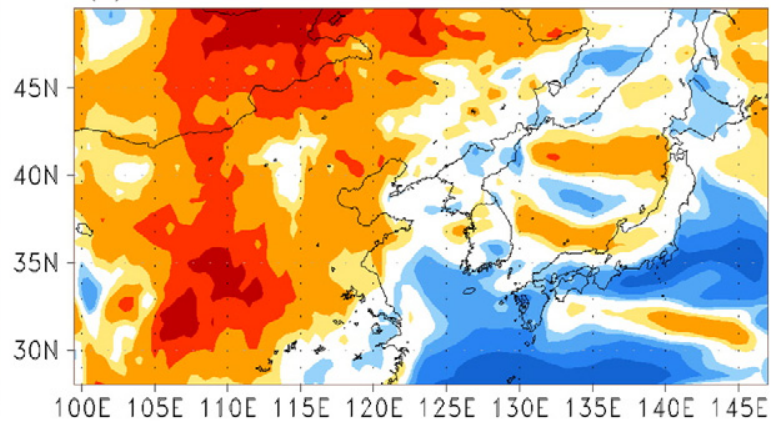

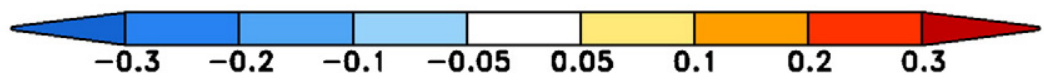

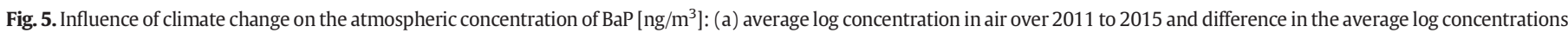
between 2011-2015 and (b) 2021-2040, (c) 2041-2060, (d) 2061-2080, and (e) 2081-2100. 
water and Phe, Flr, and BghiP in sediment were predicted to be statistically different from observation largely by a factor of less than 5 .

The analysis of the association (Table 2) confirmed that the change in the atmospheric concentration as influenced by meteorological and environmental variables is statistically well predicted by the model. This demonstrates the model's capability to account for the influences of CC on the long range transport of chemicals. However, there was statistical difference in the association between the observed and the predicted concentrations of Phe and $\mathrm{BaP}$ in water and sediment and $\mathrm{BaP}$ and BghiP in soil because knowledge on aquatic processes dynamics is lacking in the area.

According to the quantitative comparison of the predicted and observed concentration, the predictive power of the model for the atmospheric concentration is statistically significant in both the coincidence and the association. Therefore, this model may successfully predict the long range transport of the compounds as influenced by CC. The predictive power of the model for other media depends on the compounds. The predicted concentrations of Phe in water and sediment, $\mathrm{BaP}$ in water, and BghiP in sediment also show statistically significant coincidence and association with the observed data. However, this model appears to be less confident in predicting influences of CC on the concentration of the heavy PAHs in soil while the bias of the predicted value may not be statistically different from the observed. Also, the CC influences are not likely to be quantitatively accounted for by the model for some compounds (e.g., Phe and $\mathrm{BaP}$ ) in water and sediment.

\subsection{Example of POPSLTEA prediction}

To illustrate the simulation results, the case of $\mathrm{BaP}$ is presented as an example where sediment results were not included for conciseness.

\subsubsection{Air}

Fig. 5(a) shows the geometric mean value of monthly geometric mean concentrations of BaP in air during the base period (2011-2015) when the influence of CC is considered to be minimal. The areas of high atmospheric concentration generally coincide with the areas of heavy emission. In the present work, the CC influence on the concentration is denoted by the difference in logarithm of the annual geometric mean concentration between a future period and the base period, which is essentially a logarithm of the ratio of the concentrations between the two periods. The prediction results are shown in Fig. 5(b), (c), (d), and (e) for the four future periods (i.e., each 20 years from 2021 to 2100). The BaP concentration in air increases in most of the inland areas commonly in all the four future periods of CC. Increase of over a factor of 2 is predicted for the annual geometric mean concentration in the areas of northern and central China and Mongolia in the model domain. The increase in the atmospheric concentration in the inland areas is largely attributable to the decrease in atmospheric deposition. The decrease in the atmospheric deposition is caused by the change in temporal pattern of precipitation. In most sea areas, the atmospheric concentration is predicted to decrease except that located between North Korea and Japan. The decrease in the sea areas is due to reduction of wind that carries BaP from inland areas to the sea, e.g., CC increases north wind in southern China and southwest wind in southeast China.

\subsubsection{Soil and water}

The changes due to $\mathrm{CC}$ in the BaP concentrations in soil and water are shown in Fig. 6(a) and (b), respectively. Only the last future period (2081-2100) is presented because the changes in space were similar in other periods. Throughout the model domain, the concentration in soil is relatively high in the areas of heavy emission including Eastern China, South Korea, and Japan. The concentration tends to be increased (a)

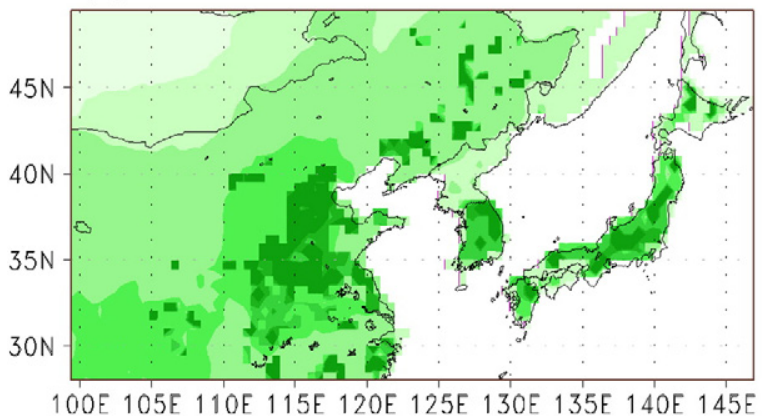

(b)

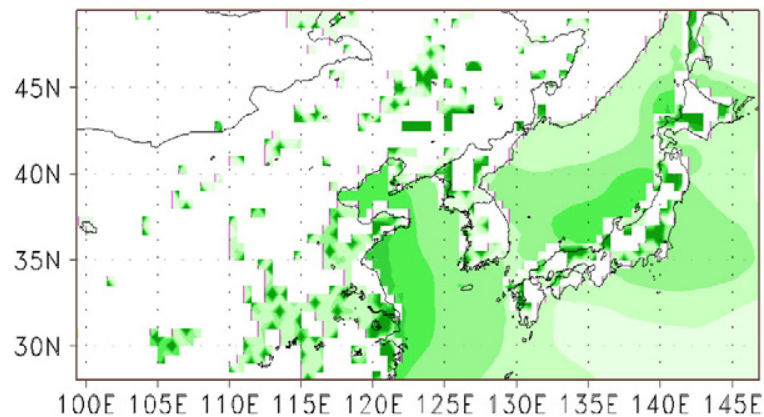

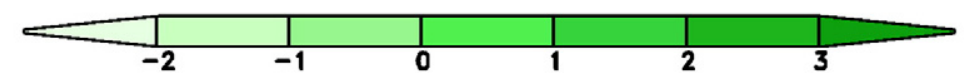

(c)

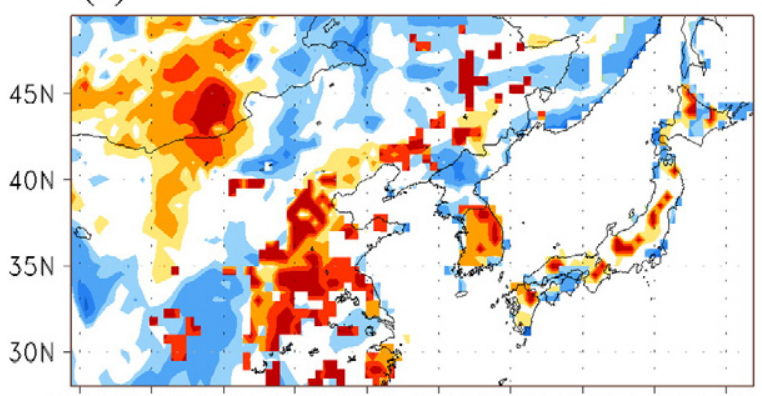

(d)

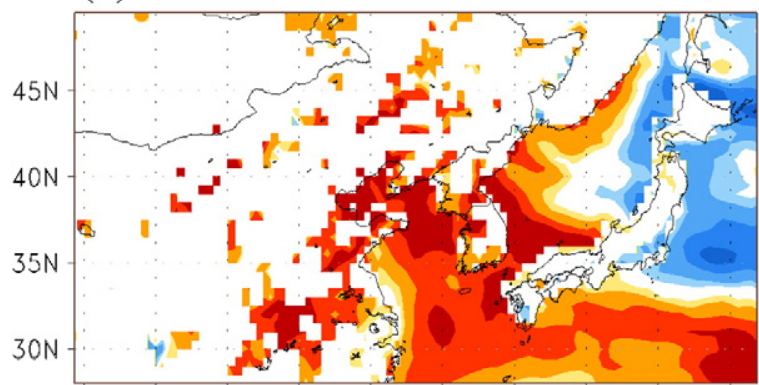

100E 105E 110E 115E 120E 125E 130E 135E 140E 145E

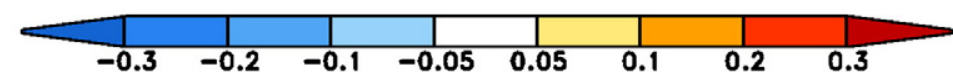

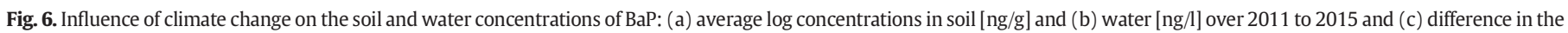
average log concentrations between 2011-2015 and 2081-2100 in soil and (d) water. 
by CC in these areas of heavy emission. Contrarily, the concentration decreases with CC in the areas where the concentration is relatively low during the base period (e.g., Central China, North Korea, and a part of Russia in the model domain). These predictions imply that CC may polarize the soil pollution problem, i.e., aggravate the pollution level in soil that is already at relatively high level and drop the pollution level in relatively clean areas. However, an opposite trend is also predicted that the pollution level increases under the CC conditions in some areas of Mongolia where the pollution level is low during the base period. This increase occurs when CC acts to raise BaP load onto soil by enhancing the atmospheric flux from surrounding areas that are more polluted than the areas of concern. The concentration in surface waters changes with CC in similar ways to that in soil, i.e., the pollution level rises in already relatively polluted areas while it declines in less polluted areas. In the sea water, however, it is evident in Fig. 6(d) that the change is smaller near the shore areas where the pollution level is comparatively high during the base period while greater concentration change occurs in relatively clean off-shore areas.

\section{Conclusion}

The spatial change of the geometric mean concentration over the 80 years (2021-2100) is predicted to range from $88 \%$ to $304 \%$, from $84 \%$ to $109 \%$, from $32 \%$ to $362 \%$, and from $49 \%$ to $303 \%$, in air, soil, surface water, and sea water, respectively. In conclusion, the model prediction strongly demonstrates that the direction and the strength of CC influences on the pollution levels of BaP vary with the location and environmental media. However, the spatial pattern of the concentration change across the model domain stays similar regardless of the four 20 year periods in the future.

\section{Acknowledgements}

This study was funded by NRF, KEITI, and Korea Ministry of Environment under the "Environmental Health Action Program" with contract numbers of 2011-0016767, 412-111-003, and 2014001370001, respectively.

\section{Appendix A. Supplementary data}

Supplementary data to this article can be found online at http://dx. doi.org/10.1016/j.scitotenv.2016.06.127.

\section{References}

Amell, N.W., Halliday, S.J., Battarbee, R.W., Skeffington, R.A., Wade, A.J., 2015. The implications of climate change for the water environment in England. Prog. Phys. Geogr. 39, 93-120.

Balbus, J.M., Boxall, A., Fenske, R.A., McKone, T.E., Zeise, L., 2013. Implications of global climate change for the assessment and management of human health risks of chemicals in the natural environment. Environ. Toxicol. Chem. 32, 62-78.

Cai, J.J., Song, J.H., Lee, Y., Lee, D.S., 2014. Assessment of climate change impact on the fates of polycyclic aromatic hydrocarbons in the multimedia environment based on model prediction. Sci. Total Environ. 470, 1526-1536.

Dalla, V.M., Marcomini, A., Sfriso, A., Sweetman, A.J., Jones, K.C., 2003. Estimation of PCDD/ F distribution and fluxes in the Venice Lagoon, Italy: combining measurement and modelling approaches. Chemosphere 51, 603-616.

Dalla, V.M., Codato, E., Marcomini, A., 2007. Climate change influence on POPs distribution and fate: A case study. Chemosphere 67, 1287-1295.

Demographia World Urban Areas, 2014. 11th ed. Demographia. www.demographia.com/ db-worldua.pdf (accessed 14.10.02).

Earnshaw, M.R., Jones, K.C., Sweetman, A.J., 2015. A first European scale multimedia fate modelling of BDE-209 from 1970 to 2020. Environ. Int. 74, 71-81.

Fairlie, T.D., Jacob, D.J., Dibb, J.E., Alexander, B., Avery, M.A., Donkelaar, A., et al., 2010. Impact of mineral dust on nitrate, sulfate, and ozone in transpacific Asian pollution plumes. Atmos. Chem. Phys. 10, 3999-4012.

Gusev, A., MacLeod, M., Bartlett, P., 2012. Intercontinental transport of persistent organic pollutants: a review of key findings and recommendations of the task force on hemispheric transport of air pollutants and directions for future research. Atmos. Pollut. Res. 3, 463-465.
Hansen, K.M., Christensen, J.H., Geels, C., Silver, J.D., Brandt, J., 2015. Modelling the impact of climate change on the atmospheric transport and the fate of persistent organic pollutants in the Arctic. Atmos. Chem. Phys. 15, 6549-6559.

Harley, C.D., Randall Hughes, A., Hultgren, K.M., Miner, B.G., Sorte, C.J., Thornber, C.S., et al. 2006. The impacts of climate change in coastal marine systems. Ecol. Lett. 9, 228-241.

Hauck, M., Huijbregts, M.A., Armitage, J.M., Cousins, I.T., Ragas, A.M., van de Meent, D. 2008. Model and input uncertainty in multi-media fate modeling: benzo [a] pyrene concentrations in Europe. Chemosphere 72, 959-967.

IGBP-MODIS land cover, d. http://webmap.ornl.gov/wcsdown/dataset.jsp?ds_id=10004/.

Jacobson, M.Z., 2005. Fundamentals of Atmospheric Modeling. second ed. CAMBRIDGE University Press, New York.

Jones, C., Hughes, J., Bellouin, N., Hardiman, S., Jones, G., Knight, J., et al., 2011. The HadGEM2-ES implementation of CMIP5 centennial simulations. Geosci. Model Dev. 4, 543-570.

Kallenborn, R., Halsall, C., Dellong, M., Carlsson, P., 2012. The influence of climate change on the global distribution and fate processes of anthropogenic persistent organic pollutants. J. Environ. Monit. 14, 2854-2869.

KME, 2008. Policy Based Research for Management of Risk to Media Integration. Korea Ministry of environment, South Korea.

Kusunoki, K., Sakata, M., Tani, Y., Seike, Y., Ayukawa, K., 2012. Evaluating the contribution of long-range transport of heavy metals from the Asian continent to their concentrations in sediment cores from Lake Shinji, western Japan. Water Air Soil Pollut. 223, 1151-1160.

Lamon, L., Dalla Valle, M., Critto, A., Marcomini, A., 2009a. Introducing an integrated climate change perspective in POPs modelling, monitoring and regulation. Environ. Pollut. 157, 1971-1980.

Lamon, L., von Waldow, H., MacLeod, M., Scheringer, M., Marcomini, A., Hungerbühler, K. 2009b. Modeling the global levels and distribution of polychlorinated biphenyls in air under a climate change scenario. Environ. Sci. Technol. 43, 5818-5824.

Law, R.J., Covaci, A., Harrad, S., Herzke, D., Abdallah, M.A.-E., Fernie, K., et al., 2014. Levels and trends of PBDEs and HBCDs in the global environment: status at the end of 2012 Environ. Int. 65, 147-158.

Lee, Y., Lee, D.S., Kim, S.K., Kim, Y.K., Kim, D.W., 2004. Use of relative concentration to evaluate a multimedia model for PAHs in the absence of emission estimates. Environ. Sci. Technol. 38, 1079-1088.

Liang X.-Z., Kunkel, K.E. Samel, A.N. 2001. Development of a regional climate model for US Midwest applications. Part I: sensitivity to buffer zone treatment. J. Clim. 14, 4363-4378.

Lin, T., Hu, L., Guo, Z., Qin, Y., Yang, Z., Zhang, G., et al., 2011. Sources of polycyclic aromatic hydrocarbons to sediments of the Bohai and Yellow Seas in East Asia. J. Geophys. Res.Atmos. 116, D23305.

Liu, S., Lu, Y., Wang, T., Xie, S., Jones, K.C., Sweetman, A.J., 2014. Using gridded multimedia model to simulate spatial fate of Benzo $[\alpha]$ pyrene on regional scale. Environ. Int. 63, 53-63.

Macdonald, R.W., Mackay, D., Li, Y.-F., Hickie, B., 2003. How will global climate change affect risks from long-range transport of persistent organic pollutants? Hum. Ecol. Risk. Assess. 9, 643-660.

MacLeod, M., Woodfine, D.G., Mackay, D., McKone, T., Bennett, D., Maddalena, R., 2001 BETR North America: a regionally segmented multimedia contaminant fate model for North America. Environ. Sci. Pollut. Res. 8, 156-163.

MacLeod, M., Riley, W.J., Mckone, T.E., 2005. Assessing the influence of climate variability on atmospheric concentrations of polychlorinated biphenyls using a global-scale mass balance model (BETR-Global). Environ. Sci. Technol. 39, 6749-6756.

MacLeod, M., von Waldow, H., Tay, P., Armitage, J.M., Wöhrnschimmel, H., Riley, W.J., et al., 2011. BETR global-a geographically-explicit global-scale multimedia contaminant fate model. Environ. Pollut. 159, 1442-1445.

Marquès, M., Mari, M., Audí-Miró, C., Sierra, J., Soler, A., Nadal, M., Domingo, J.L., 2016. Climate change impact on the $\mathrm{PAH}$ photodegradation in soils: Characterization and metabolites identification. Environ. Int. 89-90, 155-165.

Nadal, M., Marquès, M., Mari, M., Domingo, J.L., 2015. Climate change and environmental concentrations of POPs: A review. Environ. Res. 143, 177-185.

NIMR, 2011. Report of Climate Change Scenario for IPCC 5th Evaluation. National Institute of Meteorological Research, South Korea.

NIMR, 2012. Report of Global Climate Change for IPCC 5th Evaluation. National Institute of Meteorological Research, South Korea.

Noyes, P.D., McElwee, M.K., Miller, H.D., Clark, B.W., Van Tiem, L.A., Walcott, K.C., et al., 2009. The toxicology of climate change: environmental contaminants in a warming world. Environ. Int. 35, 971-986.

OSCAR, d. http://www.oscar.noaa.gov/datadisplay/oscar_datadownload.php/.

OSPAR, d. http://www.ospar.org.

Schiedek, D., Sundelin, B., Readman, J.W., Macdonald, R.W., 2007. Interactions between climate change and contaminants. Mar. Pollut. Bull. 54, 1845-1856.

Shen, H., Tao, S., Wang, R., Wang, B., Shen, G., Li, W., et al., 2011. Global time trends in PAH emissions from motor vehicles. Atmos. Environ. 45, 2067-2073.

Smith, J., Smith, P., 2007. Environmental Modelling: An Introduction. Oxford University Press, New York

Stott, P.A., Jones, G.S., Lowe, J.A., Thorne, P., Durman, C., Johns, T.C., et al., 2006. Transient climate simulations with the HadGEM1 climate model: causes of past warming and future climate change. J. Clim. 19, 2763-2782.

Teran, T., Lamon, L., Marcomini, A., 2012. Climate change effects on POPs' environmental behaviour: a scientific perspective for future regulatory actions. Atmos. Pollut. Res. 3 , 466-476.

The Maddison-Project, 2013. http://www.ggdc.net/maddison/maddison-project/home htm/.

Tobiszewski, M., Namiesnik, J., 2012. PAH diagnostic ratios for the identification of pollution emission sources. Environ. Pollut. 162, 110-119. 
USGS, d. Long term archivehttps://lta.cr.usgs.gov/HYDR01K/.

Wang, Z., Xie, F., Sakurai, T., Ueda, H., Han, Z., Carmichael, G., et al., 2008. MICS-Asia II: Model inter-comparison and evaluation of acid deposition. Atmos. Environ. 42 $3528-3542$.

Wania, F., 2003. Assessing the potential of persistent organic chemicals for long-range transport and accumulation in polar regions. Environ. Sci. Technol. 37, 1344-1351.

Wania, F., Daly, G.L., 2002. Estimating the contribution of degradation in air and deposition to the deep sea to the global loss of PCBs. Atmos. Environ. 36, 5581-5593.

Wania, F., Mackay, D., 1999. The evolution of mass balance models of persistent organic pollutant fate in the environment. Environ. Pollut. 100, 223-240.

World Bank, d. http://data.worldbank.org/indicator/NY.GDP.MKTP.KD.ZG/.
Xu, S., Liu, W., Tao, S., 2006. Emission of polycyclic aromatic hydrocarbons in China. Environ. Sci. Technol. 40, 702-708.

Zhang, Y., Tao, S., 2009. Global atmospheric emission inventory of polycyclic aromatic hydrocarbons (PAHs) for 2004. Atmos. Environ. 43, 812-819.

Zhang, Y., Tao, S., Cao, J., Coveney, R.M., 2007. Emission of polycyclic aromatic hydrocarbons in China by county. Environ. Sci. Technol. 41, 683-687.

Zhu, Y., Price, O.R., Tao, S., Jones, K.C., Sweetman, A.J., 2014. A new multimedia contaminant fate model for China: How important are environmental parameters in influencing chemical persistence and long-range transport potential? Environ. Int. 69, 18-27. 